\title{
Quarenta anos de Escola Francesa da Regulação: entre o marxismo e o institucionalismo histórico *
}

\author{
Marcelo Soares Bandeira de Mello Filho **
}

\begin{abstract}
Resumo
A escola francesa da regulação se originou em meados da década de 1970, tendo como objetivo principal desenvolver e atualizar a análise de Marx do modo de produção capitalista para compreender as transformações econômicas do século XX. Essa é a origem dos conceitos de regime de acumulação, modo de regulação, formas institucionais e fordismo. A partir da década de 1980, a abordagem tornou-se menos próxima do marxismo e mais preocupada em elaborar uma economia histórica e institucional. As décadas de 1980 e 1990 foram vistas como um período de continuidade da crise do fordismo. Foi somente a partir do ano 2000 que os autores regulacionistas vislumbraram a possibilidade de existência de um regime de acumulação liderado pelas finanças, que teria entrado em crise em 2008. A dificuldade de compreender o capitalismo posterior ao fordismo está associada a uma visão teórica inadequada acerca das características básicas do modo de produção.
\end{abstract}

Palavras-chave: Escola francesa da regulação; Capitalismo contemporâneo; Institucionalismo histórico.

\section{Abstract}

\section{Forty years of the French regulation school: alternating between marxism and historical institutionalism}

The French regulation school originated in the mid-1970s, with the aim of developing and updating Marx's analysis of capitalism, in order to understand the economic transformations of the twentieth century. This marks the origin of the regime of accumulation, mode of regulation, institutional forms and Fordism concepts. Since the 1980s, the school has distanced itself from Marxism and has become more concerned with developing a historical and institutional approach. It was only after 2000 that the regulation approach identified the possibility of the existence of a finance-led regime of accumulation, argued by the school to have collapsed after the 2008 crisis. The problems that the French regulation school has in understanding capitalism from the 1980s onwards are associated with an inadequate theoretical view on the basic characteristics of the capitalist mode of production.

Keywords: French regulation school; Contemporary capitalism; Historical institutionalism.

JEL B24, B25, B51, B52.

\section{Introdução}

O artigo tem por objetivo a compreensão crítica do surgimento e das transformações do projeto teórico da escola francesa da regulação ${ }^{1}$, tendo como foco principal as

* Artigo recebido em 30 de maio de 2017 e aprovado em 2 de janeiro de 2018. O presente artigo foi baseado no terceiro capítulo da tese de doutorado do autor (Mello Filho, 2016), defendida no Cedeplar/UFMG, em 2016. A tese foi beneficiada pelos comentários de Carlos Eduardo Suprinyak, Eduardo da Motta e Albuquerque, Eleutério Prado, David Dequech e pela orientação de Hugo Eduardo Araujo da Gama Cerqueira. O trabalho também foi beneficiado pelos comentários do parecerista anônimo. Nenhum dos citados possui responsabilidade pelos equívocos presentes no artigo.

${ }^{* *}$ Professor Adjunto da Universidade Federal de São João del-Rei (UFSJ), São João del-Rei, MG, Brasil. E-mail: marcelosbmf@gmail.com.

(1) É importante sublinhar que o termo regulação não se refere ao uso mais comum em economia, sinônimo de regulamentação, mas diz respeito à reprodução e à transformação do capitalismo, apreendidas por meio de conceitos que captem as regularidades observadas em determinada época. 
modificações dos conceitos centrais da escola: formas institucionais, modo de regulação e regime de acumulação ${ }^{2}$. Devido à opção metodológica de analisar criticamente as mudanças do projeto teórico regulacionista desde sua origem até o período atual, o presente artigo pretende preencher algumas lacunas da literatura, tanto aquela publicada em português quanto a publicada em idioma estrangeiro (Possas, 1988; Nascimento, 1993; Brenner, Glick, 1991; Jessop, Sum, 2006, 2016; Mavroudeas, 2006; Vidal, 2001; Husson, 2009). Tais lacunas se referem à análise de apenas algumas das gerações de trabalhos regulacionistas ou à falta de uma análise aprofundada acerca dos problemas teóricos da abordagem da regulação (AR).

A escola francesa da regulação se originou em meados da década de 1970, tendo como objetivo principal compreender as transformações econômicas da época. Os fundadores da corrente, entre os quais se destacam Boyer, Aglietta e Lipietz, foram motivados tanto pela tentativa de superação do marxismo convencional da época ${ }^{3}$, quanto pela busca da compreensão dos limites dos modelos macroeconômicos de inspiração keynesiana. A principal discordância dos autores regulacionistas em relação a essas correntes é a incapacidade que tanto o marxismo convencional quanto o keynesianismo da época teriam, de captar as mudanças históricas, as transformações qualitativas do modo de produção capitalista (Aglietta, 1979, 1994; Coriat, 1994a; Boyer, 1990, 2004, 2015). Essa mesma crítica é dirigida, inclusive, à teoria neoclássica da época, seja na sua versão do equilíbrio geral, seja na versão da síntese neoclássica.

Nos trabalhos iniciais da escola, buscou-se partir da análise marxista e construir conceitos intermediários entre os de Marx e as variáveis atuais da economia, para dar conta de compreender as mudanças econômicas do pós-guerra. Posteriormente, a escola se afastou desse projeto teórico inicial e passou a desenvolver uma economia histórica e institucional, que procurou não adotar nenhuma concepção sobre as características fundamentais do capitalismo. Entretanto a escola não conseguiu desenvolver uma abordagem puramente histórica e acabou adotando concepções pré-teóricas acerca dos fundamentos do modo de produção capitalista.

Para a escola francesa da regulação, a acumulação de capital depende de um conjunto de instituições para se viabilizar. Cinco formas institucionais são destacadas: a relação salarial, a moeda, as formas da concorrência, o Estado e o tipo de inserção internacional. O conjunto de instituições forma um modo de regulação, o arcabouço institucional que garante a viabilidade de um determinado padrão de crescimento (um regime de acumulação) em um espaço específico e por um determinado período de tempo. Quando o regime de acumulação

(2) Não há apenas uma abordagem de economia na França que utilize com frequência o conceito de regulação. Há pelo menos três dessas abordagens: a escola parisiense, a escola de Grenoble e a escola de Boccara. No presente trabalho será analisada com profundidade apenas a vertente parisiense, considerada a mais importante. Para fins de fluência do texto, serão utilizados os termos escola francesa da regulação, abordagem francesa da regulação e abordagem da regulação (AR) para se referir à mesma corrente, a escola parisiense da regulação.

(3) As correntes do marxismo criticadas pelos autores regulacionistas são, principalmente, o estruturalismo althusseriano, as teorias do imperialismo, as teorias da dependência e as abordagens do capitalismo monopolista de Estado. 
ou o modo de regulação entram em crise, tem início um período de mudança institucional, que pode dar origem a um novo tipo de capitalismo.

O restante do texto se estrutura da seguinte maneira: na próxima seção será discutido o ambiente intelectual francês no qual emergiu a abordagem da regulação. Em seguida, serão analisados os elementos teóricos presentes nos textos fundadores. Na sequência serão discutidos os elementos teóricos das obras fundamentais das décadas de 1980 e 1990. Em seguida, serão analisadas obras voltadas à compreensão do capitalismo contemporâneo e por fim será feita uma avaliação crítica da contribuição da escola.

\section{Antecedentes da abordagem da regulação}

As reflexões da AR emergiram no contexto de estagflação dos anos 1960 e 1970, procurando esclarecer tanto as razões para o período de elevado crescimento do pós-guerra, quanto a especificidade da estagflação, bastante diferente da espiral deflacionária da Grande Depressão. O pós-guerra na França foi marcado, no plano econômico, pela reconstrução da economia. No âmbito político, os partidos e grupos gaullistas, comunistas, socialistas e democratas-cristãos formaram a coalizão que governou o país. Nesse mesmo período, a sociedade francesa passou por uma série de transformações estruturais, que incluem o direito das mulheres ao voto, a implantação de um sistema de seguridade social, a implantação de um setor público industrial e financeiro, além da criação de órgãos estatais de planejamento, responsáveis, nesse primeiro momento, pelo projeto de reconstrução da economia francesa ${ }^{4}$.

Em meados dos anos 1970, os principais autores regulacionistas (Boyer, Aglietta e Lipietz) trabalhavam em órgãos de planejamento do governo francês ${ }^{5}$. O papel dos economistas nesses órgãos incluía a interpretação de dados de médio e longo prazo e a construção de modelos macroeconométricos de inspiração keynesiana. Entretanto, depois da segunda metade dos anos 1960, assim como em outras partes do mundo, notadamente nos Estados Unidos, os modelos keynesianos não mais apresentavam boas predições, especialmente da relação entre inflação e desemprego, sintetizada pela curva de Phillips. Porém, diferentemente do que aconteceu nos Estados Unidos, onde a heterodoxia era bastante minoritária e prevaleceu a ascensão do monetarismo, parte relevante dos economistas franceses foi buscar explicações para a quebra da estabilidade na relação entre inflação e desemprego em Keynes, Kalecki, Marx e uma variedade de economistas heterodoxos.

(4) Entre as organizações de planejamento destacam-se o Institut National de la Statistique et des Études Économiques (INSEE), responsável por coletar e produzir informações sobre a economia francesa, o Service des Études Économiques et Financières (SEEF), que calcula as contas nacionais e o orçamento, depois renomeado para Direction de la Prévision (DP) e, finalmente, o Commissariat Général du Plan, órgão que realizava o planejamento da economia, com base na negociação e no diálogo entre o Estado, os empresários e os sindicatos (Vidal, 2001, p. 14-15).

(5) Na década de 1970, Aglietta trabalhou no INSEE, Boyer no Centre d'Études des Revenus et des Coûts (CERC) e, posteriormente, na Direction de la Prévision, e Lipietz no Centre d'Études Prospectives d'Économie Mathématique Appliquées à la Planification (Cepremap). Tanto o Cepremap quanto o CERC são associados ao Commissariat Général du Plan (Vidal, 2001, p. 14-15). 
As primeiras obras dos autores que mais tarde fundariam a abordagem da regulação procuravam desenvolver e refinar modelos macroeconômicos e econométricos de inspiração keynesiana, utilizados nos órgãos de planejamento (Aglietta; Courbis, 1969; Boullé; Boyer, Mazier; Gaston, 1974). Em um segundo momento, os autores exploram as limitações de tais modelos, analisando-os de forma crítica (Aglietta, 1971; Boyer, 1976). Os textos críticos aos modelos macroeconométricos apresentam importantes elementos que viriam a fazer parte do pensamento regulacionista.

Aglietta (1971) realiza um estudo detalhado das mudanças salariais na França. A preocupação com o mundo do trabalho, a diferenciação entre regimes de crescimento com menor grau de inovação tecnológica (crescimento extensivo) e aqueles nos quais a produtividade aumenta com maior rapidez (crescimento intensivo) e a concepção de que a economia não pode ser entendida sem se levar em conta o Estado (que contribui com a formação da força de trabalho, demanda produtos específicos ou apenas garante um arcabouço jurídico para o funcionamento dos mercados) são algumas características desse texto que marcarão a escola da regulação.

Boyer (1976) procura explicar a sucessão dos modelos macroeconômicos como resultado das mudanças nas formas institucionais que prevaleceriam em determinado período, a "regulação de conjunto". Esta, por sua vez, já se encontra baseada nas cinco formas institucionais que nortearão a investigação da AR: a organização da moeda e do crédito; a inserção internacional; a relação de trabalho; a forma das estruturas industriais e o padrão de ação estatal.

O conceito de regulação já era utilizado pela economia marxista francesa anteriormente às obras de Aglietta, Boyer e Lipietz sobre o assunto. Os primeiros usos do termo se deram com os trabalhos de Paul Boccara e Destanne de Bernis. Segundo Jessop e Sum (2006, p. 18-24), foi Boccara quem primeiro utilizou a expressão, no debate acerca do capitalismo monopolista de Estado, travado no âmbito do Partido Comunista Francês. O conceito de regulação foi utilizado para descrever os fenômenos de sobreacumulação e de desvalorização do capital, que regulariam a lei da tendência decrescente da taxa de lucro (Boccara, 1971, 1978) ${ }^{6}$. Depois disso, o conceito foi introduzido na escola de Grenoble marcada pela contribuição de Perroux e Palloix -, na qual Destanne de Bernis se insere como o principal desenvolvedor de uma análise em termos de regulação. Em Grenoble foi fundado o GRREC, Groupe de Recherche sur la Régulation d'Économies Capitalistes, que identifica três tipos de capitalismo: concorrencial, monopolista e monopolista de Estado. Ainda de acordo com Jessop e Sum (2006, p. 31-34), embora Boccara tenha utilizado primeiro o conceito de regulação, o fez de modo pré-teórico. O conteúdo teórico do termo foi desenvolvido simultaneamente, ao longo da década de 1970, pelas três correntes regulacionistas francesas, que se influenciaram mutuamente e se diferenciaram ao longo do

(6) As ênfases no capitalismo monopolista e na tendência decrescente da taxa de lucro foram criticadas por autores regulacionistas, como Aglietta (1979, p. 353-356; 381-383), Coriat (1994a) e Boyer (2015, p. 43). 
tempo ${ }^{7}$. O próximo item explorará os textos fundadores da escola parisiense da regulação, tendo como foco principal os conceitos centrais da escola.

\section{Trabalhos fundadores}

A obra de Michel Aglietta, "Régulation et crises du capitalisme" baseou-se na tese de doutorado defendida em 1974. O livro foi publicado na França em $1976^{8}$ e nos Estados Unidos em 1979, com o título de "A theory of capitalist regulation: the US experience". É considerada a obra na qual a abordagem francesa da regulação é sistematizada pela primeira vez. A maneira como o argumento de Aglietta (1979) é organizado é a seguinte: o autor parte da análise de Marx do modo de produção capitalista, para depois construir novos conceitos, menos abstratos, derivados das transformações no processo de trabalho, para, por fim, realizar uma exposição acerca do desenvolvimento histórico do capitalismo estadunidense. Esta exposição, por sua vez, é centrada nas mudanças nas normas de produção e consumo, nas transformações da relação monetária e nas formas específicas de crise econômica. A estratégia adotada permitiria "desenvolver o potencial dos conceitos de Marx empregando-os em um estudo crítico das principais transformações sociais do século passado" (Aglietta, 1979, p. 17) ${ }^{9}$.

Portanto, Aglietta procura, primeiramente, interpretar a teoria do valor de Marx ${ }^{10}$. O autor afirma que não é objetivo da obra de Marx estabelecer uma teoria dos preços. Na verdade, a teoria do valor de Marx procuraria apreender a relação capital-trabalho e as leis da acumulação e da competição no sistema capitalista, responsáveis pela reprodução do trabalho social e pela distribuição do mesmo entre duas classes sociais: a burguesia e o proletariado (Aglietta, 1979, p. 18). A concorrência faria com que os capitalistas procurassem sempre produzir de forma mais barata e uma das formas de se fazer isso seria produzindo mais valor absoluto, que poderia ser extraído tanto por meio da ampliação da jornada de trabalho quanto por meio da diminuição das porosidades da jornada de trabalho. Outra forma de reduzir custos se daria pela diminuição do tempo de trabalho socialmente necessário, ou seja, produzindo mais valor relativo.

(7) Além da escola de Grenoble e da abordagem de Boccara, que se desenvolveram simultaneamente à escola parisiense da regulação, Jessop e Sum (2006) identificam a escola das estruturas sociais de acumulação como uma abordagem bastante próxima da AR e consideram que esta influenciou (juntamente com o marxismo, o keynesianismo e o institucionalismo) o surgimento de outras correntes, como a escola de Amsterdã, mais voltada à economia política internacional, a escola Alemã Ocidental, que enfatiza a teoria do Estado, e a escola Nórdica, voltada para a compreensão da regulação de pequenas economias abertas, principalmente os países escandinavos. No presente artigo, somente a escola parisiense da regulação será analisada em detalhe.

(8) O ano de 1976 é considerado, simbolicamente, o ano de início da escola (Boyer, 1990, 2015, p. 325).

(9) "The objective of this work, in other words, is to develop the potential of Marx's concepts by deploying them in a critical study of the major social transformations of the past century" (Aglietta, 1979, p. 17).

(10) É importante destacar que, no que se refere à interpretação da obra de Marx na França dos anos 1960 e 1970, a obra de Louis Althusser era a principal referência. O autor desenvolveu o marxismo estruturalista, que foi uma das influências da escola francesa da regulação. 
Para a escola francesa da regulação, não existe uma única natureza humana e tampouco um único tipo imutável de capitalismo. O comportamento humano é mais complexo, passível de explicações que procuram dar conta dos diferentes tipos de lógicas sociais e das suas mudanças no tempo e no espaço. Tais comportamentos servem de base ao conceito de instituição. Este conceito é o elemento central que permite a adoção de um ponto de vista historicista na escola da regulação. Os termos formas estruturais e formas institucionais são utilizados para identificar as diferentes maneiras nas quais as relações sociais básicas do capitalismo (relação capital-trabalho, concorrência e relação monetária) aparecem ao longo da história: "Devemos usar o termo formas estruturais para as relações sociais básicas, organizadas em instituições, que são os produtos históricos da luta de classes" (Aglietta, 1979, p. 19) ${ }^{11}$.

Entretanto, desde o texto fundador de Aglietta há, no âmbito da AR, uma tensão, que não é bem resolvida, entre, por um lado, a caracterização geral do modo de produção capitalista e, por outro lado, a compreensão do sistema econômico como um conjunto de instituições que são sempre historicamente determinadas e, por isso, não podem ser analisadas de um ponto de vista a-histórico, estrutural, abstrato, seja tal ponto de vista de natureza neoclássica, keynesiana ou mesmo marxista. Na passagem a seguir, por exemplo, o autor enfatiza o equívoco do estudo de leis econômicas abstratas: "O estudo da regulação capitalista, portanto, não pode ser a investigação de leis econômicas abstratas. É o estudo da transformação das relações sociais na medida em que elas criam formas novas, que são tanto econômicas quanto não-econômicas, que são organizadas em estruturas e reproduzem elas mesmas uma estrutura determinante, o modo de produção" (Aglietta, 1979, p. 16) ${ }^{12}$. Essa citação expressa a tensão entre uma abordagem historicista, contrária às "leis econômicas abstratas" e a existência de uma "estrutura determinante, o modo de produção". Será mostrado a seguir que a própria obra pioneira de Aglietta não adota um ponto de vista historicista, ao se apoiar, pelo menos parcialmente, em leis econômicas abstratas ${ }^{13}$.

Aglietta realiza sua análise do capitalismo americano tendo por base uma interpretação particular dos esquemas de reprodução de Marx. O argumento principal do livro pode ser resumido em algumas observações sobre a lógica do sistema capitalista, o que contradiz a pretensão historicista de Aglietta e aproxima a obra ao método estruturalista. Aglietta (1979) advoga a tendência ao desenvolvimento desigual dos dois departamentos da produção capitalista. O departamento I, produtor de bens de capital, tenderia a ter suas forças produtivas revolucionadas mais rapidamente que o departamento II, produtor de bens de consumo, o que geraria a possibilidade da ocorrência de crises de desproporção. Tal problema

(11) "We shall use the term structural forms for the basic social relations, organized in institutions, that are the historical products of the class struggle" (Aglietta, 1979, p. 19).

(12) "The study of capitalist regulation, therefore, cannot be the investigation of abstract economic laws. It is the study of the transformation of social relations as it creates new forms that are both economic and non-economic, that are organized in structures and themselves reproduce a determinant structure, the mode of production" (Aglietta, 1979, p. 16).

(13) Mais à frente, será concluído que a falta de uma análise adequada da "estrutura determinante, o modo de produção", será uma insuficiência séria da abordagem. 
seria evitado, por sua vez, se o segundo setor, produtor de bens de consumo, crescesse de tamanho. $\mathrm{O}$ setor de bens de consumo cresceria se os trabalhadores começarem a consumir mais:

A acumulação capitalista necessariamente encontra obstáculos. Ela deriva seu impulso do desenvolvimento desigual do Departamento I. Mas este desenvolvimento desigual encontra uma barreira no curso da acumulação. Esta barreira, que é sempre latente, só pode ser superada se a produção capitalista revolucionar as condições de existência da classe assalariada. É somente por meio dessa transformação social que a produção de mercadorias pode alcançar um ritmo de expansão que permite pelo menos uma realização tendencial do desenvolvimento harmonioso dos dois departamentos, que é uma condição necessária para um ritmo regular de acumulação (Aglietta, 1979, p. 60$61)^{14}$.

Ficará claro ao longo do texto, que a abordagem da regulação não desenvolveu a intuição de Aglietta de que a história do capitalismo deveria ser explicada pelas mudanças nas relações entre os dois departamentos da economia. Este modelo explicativo, que se inspira no livro II de "O Capital", padece dos mesmos equívocos das interpretações de autores como Rosa Luxemburgo, Tugan-Baranovski e Hilferding, de que os esquemas de reprodução podem ser aplicados diretamente ao entendimento concreto do capitalismo ${ }^{15}$.

Entretanto, outra característica da argumentação pioneira de Aglietta foi adotada nos trabalhos ligados à escola da regulação, ainda que sofra da mesma insuficiência de base empírica e teórica: a periodização do capitalismo com base em regimes de acumulação intensiva versus extensiva. No regime de acumulação extensiva prevalece a extração de maisvalia absoluta (é um regime de baixo crescimento da produtividade), enquanto na acumulação intensiva prevalece a extração de mais-valia relativa (neste caso ocorreria elevado crescimento da produtividade). Somente no segundo regime a classe assalariada formaria uma norma de consumo em massa.

Depois de estabelecidos os conceitos básicos de sua abordagem, o autor elabora uma narrativa histórica de longa duração (que guarda paralelos com a Escola dos Anais) sobre as transformações econômicas dos Estados Unidos. As origens do regime de acumulação intensiva remontariam ao começo do século XX, quando teria ocorrido a ampliação da produtividade do trabalho advinda da introdução de técnicas tayloristas e fordistas. Porém, a demanda seria limitada pela pequena capacidade de consumo da classe trabalhadora. Tal contradição entre a crescente capacidade de produção e a restrita capacidade de consumo, que

(14) "Capitalist accumulation necessarily comes up against obstacles. It derives its impulse from the uneven development of Department I. But this uneven development meets a barrier in the course of the accumulation. This barrier, which is always latent, can only be raised if capitalist production revolutionizes the conditions of existence of the wage-earning class. It is only by this social transformation that commodity production can achieve a rhythm of expansion which permits at least a tendential realization of that harmonious development of the two departments which is a necessary condition for a regular rhythm of accumulation" (Aglietta, 1979, p. 60-61).

(15) Rosdolsky (2001) elabora uma crítica sofisticada à utilização, nas primeiras décadas do século XX, dos esquemas de reprodução para a compreensão de características concretas do capitalismo. 
seria uma das principais causas da Crise de 1929, teria sido superada pelo estabelecimento de um sistema de barganha salarial coletiva. Mais recentemente, com a crise que se iniciou no final da década de 1960, o processo teria sido análogo: a dificuldade de manter os elevados ganhos de produtividade da era de ouro acabaria por gerar a estagflação.

Enquanto Aglietta elaborava sua tese e seu livro, ele foi influenciado e influenciou grupos de pesquisadores reunidos em órgãos de planejamento franceses. Boyer e Lipietz faziam parte desses grupos de pesquisa. Um dos primeiros relatórios realizados pelo grupo e publicado apenas parcialmente foi "Approches de l'inflation: l'exemple français" (Benassy, Boyer, Lipietz, 1978). É justamente a busca de causas para a persistência da inflação que motivou esse trabalho, que viria a ser outro dos textos fundadores do regulacionismo.

A hipótese básica adotada pelos autores para resolver o enigma da estagflação era o de que ela resultaria não de choques acidentais nos preços, mas das próprias características institucionais do sistema capitalista da época: "A hipótese de base da pesquisa é a de que essas mudanças não resultam de causas acidentais, mas refletem uma mudança fundamental, ainda que muito gradual, nas economias capitalistas. Esquematizando muito grosseiramente essa evolução, nós passamos de uma regulação concorrencial a uma regulação 'monopolista' (ou 'administrada')" (Benassy; Boyer; Lipietz, 1978, p. 12) ${ }^{16}$. Por sua vez, uma regulação de conjunto monopolista, seria resultado de um regime de acumulação intensiva: "Demonstra-se então que a um regime de acumulação intensiva deve corresponder uma forma de regulação monopolista" (Benassy; Boyer; Lipietz, 1978, p. 13) ${ }^{17}$.

Os autores argumentam que a regulação de conjunto monopolista se baseia numa codificação coletiva do contrato de trabalho, que incorpora ganhos de produtividade ao salário real. Os preços passariam a ser fixados pelas maiores empresas. As políticas estatais de gasto público e de salário indireto garantiriam o equilíbrio entre oferta e demanda. O papel de emprestador de última instância, realizado pelos Bancos Centrais, favoreceria tanto a estabilização da demanda quanto a expansão monetária por parte dos bancos, inviabilizando a existência de um padrão monetário metálico (Benassy; Boyer; Lipietz, 1978, p. 14-15).

Como todo modo de regulação, a regulação monopolista não está isenta de tensões e contradições. A primeira fonte de instabilidade seria a contradição entre economias nacionais reguladas e a economia internacional, não submetida a uma regulação supranacional. A segunda contradição seria a pressão inflacionária, originária do funcionamento normal do arcabouço institucional, uma vez que esse propicia o conflito distributivo e estimula políticas macroeconômicas expansionistas (Benassy; Boyer; Lipietz, 1978).

(16) "L'hypothèse de base de la recherche est que ces changements ne résultent pas de causes accidentelles mais reflètent un changement fondamental, bien que très progressif, dans la régulation des économies capitalistes. En schématisant très grossièrement cette évolution, on passerait d'une régulation concurrentielle à une régulation 'monopoliste' (ou 'administrée')" (Benassy; Boyer; Lipietz, 1978, p. 12).

(17) 'On montre alors qu'à un 'régime d'accumulation intensive' doit correspondre une forme de 'régulation monopoliste" " (Benassy; Boyer; Lipietz, 1978, p. 13). 
As pesquisas que deram origem a esse texto de Benassy, Boyer e Lipietz também deram origem a diferentes trabalhos desses autores. Entre os mais importantes deve-se destacar o livro de Boyer e Mistral, "Accumulation, inflation, crises", publicado em 1978 e o livro de Lipietz "Le monde enchanté: de la valeur à l'envol inflationniste”, de 1983.

É justamente a descoberta das causas da aceleração inflacionária entre 1968 e 1973 um dos principais objetivos do livro de Boyer e Mistral, como o próprio título deixa claro. A crise que motivou a publicação do livro teria sido resultado de uma regulação monopolista, na qual os preços e os contratos de trabalho seriam mais rígidos e as políticas fiscais e monetárias anticíclicas impediriam o agravamento da recessão, ao mesmo tempo em que dificultariam a diminuição da inflação. A combinação de um período de menor acumulação com a ampliação das disputas pela distribuição de renda teria provocado a estagflação (Boyer; Mistral, 1978, p. 159-196).

A última obra da fase inicial da AR que será destacada é o livro "Le monde enchanté: de lavaleur à l'envol inflationniste", de 1983. Nesta obra, Lipietz diagnostica uma crise do marxismo, especialmente no campo da economia. Uma das razões para tal crise seria a ausência de soluções satisfatórias para o problema da transformação dos valores em preços. E, portanto, um dos objetivos do livro seria a proposição de uma solução para tal problema. Para lançar uma luz sobre a relação entre valores e preços, o autor considerou que os marxistas deveriam tratar de modo mais sério o mundo encantado (ou exotérico), dos preços e rendas expressos em moeda, em vez de se fixar apenas no mundo desencantado (ou esotérico) dos valores e da apropriação do trabalho social. O mundo encantado seria o mundo fetichizado dos hábitos e das instituições. Quando o mundo esotérico do trabalho social determinando os valores entra em choque com o mundo exotérico dos preços, salários, juros, lucros e aluguéis, ocorre uma crise (Lipietz, 1983, p. 128-133). Historicamente, enquanto nos anos 1930 teria havido superprodução devido à incapacidade de os salários crescerem no ritmo da produção, nos anos 1970 teria ocorrido uma diminuição dos ganhos de produtividade, provocando redução da rentabilidade e conflitos distributivos:

Desde os anos cinquenta, até meados dos anos sessenta, o crescimento dos salários e lucros nominais compensou, aproximadamente, os ganhos de produtividade. Assim, os preços nominais permaneceram relativamente estáveis. Mas, desde meados dos anos sessenta, o regime de acumulação intensiva mostra sinais de desaceleração: pode-se falar efetivamente de "crise do fordismo" (...). Os ganhos de produtividade não mais compensavam o crescimento da composição técnica do capital, e a resistência da classe trabalhadora impediu um aumento da taxa de exploração por meio de uma redução dos salários reais (Lipietz, 1983, p. 164) ${ }^{18}$.

(18) 'Depuis les années cinquante jusqu'au milieu des années soixante, la croissance des salaires et des profits nominaux a compensé approximativement les gains de productivité. Aussi les prix nominaux sont-ils restés relativement stables. Mais depuis le milieu des années soixante, le régime d'accumulation intensive montre des signes d'essoufflement: on peut effectivement parler de 'crise du fordisme' (...) Les gains de productivité n'ont plus compensé la croissance de la composition technique du capital, et la résistance de la classe ouvrière a empêché une hausse du taux d'exploration à travers une réduction du salaire réel" (Lipietz, 1983, p. 164). 
Algumas breves observações podem ser tecidas acerca dessa primeira safra de trabalhos regulacionistas. Em primeiro lugar, há uma dicotomia entre textos - Aglietta (1979) e Lipietz (1983) - que procuram desenvolver uma abordagem marxista da economia e obras Benassy, Boyer e Lipietz (1978) e Boyer e Mistral (1978) - nas quais predomina uma visão mais histórica e eclética (embora heterodoxa) da economia. Como será observado, essa segunda estratégia teórica e metodológica prevalecerá na escola da regulação. Em segundo lugar, o modo de regulação e as formas institucionais típicas do capitalismo do pós-guerra (os salários crescentes, o padrão monetário fiduciário e o Estado intervencionista) aparecem como resultado do imperativo do regime de acumulação intensiva tanto para Aglietta (1979), quanto para Benassy, Boyer e Lipietz (1978). Há um determinismo econômico e tecnológico quando é dito que as mudanças no regime de acumulação causam alterações no modo de regulação. Um último ponto que deve ser destacado é que o termo fordismo não era usado por todos os autores. Se o conceito era central para Aglietta (1979), era ausente em Benassy, Boyer e Lipietz (1978) e em Boyer e Mistral (1978). Era um tema de importância menor para Lipietz (1983).

\section{Desenvolvimentos das décadas de 1980 e 1990}

As décadas de 1980 e 1990 marcaram uma inflexão na AR. A escola, da década de 1980 em diante, se afastou da pretensão de conjugar uma análise geral do capitalismo, fundada em Marx ${ }^{19}$, com uma abordagem histórica da economia. Tal segunda etapa marca a ênfase no desenvolvimento de uma macroeconomia histórica e institucional ${ }^{20}$ (Vidal, 2001; Boyer, 2004, 2015; Lamarche, 2012; Billaudot, 2001).

Além dessa mudança fundamental na ambição teórica da escola, outras mudanças importantes ocorreram. Em meados da década de 1990, Boyer e Saillard organizaram uma obra (cuja primeira edição foi publicada em 1995 e a segunda em 2002) que contou com mais de cinquenta artigos, configurando um importante inventário dos desenvolvimentos da AR até então. Nessa obra pode-se observar como a abordagem da regulação foi sendo aprimorada e sofisticada ao longo do tempo.

A primeira evolução da teoria em relação à primeira leva de trabalhos foi a tentativa de incorporar a teorização do Estado (Théret, 2002; Jessop, Sum, 2006). A segunda novidade é a aplicação do método regulacionista a diferentes espaços geográficos, como o Japão (Coriat, 1994b), a América Latina (Lipietz, 1988; Aboites, Miotti, Quenan, 2002) e a Rússia

(19) Por um lado, a AR continuou dialogando e servindo de inspiração para autores marxistas ou inspirados em Marx, como Giovanni Arrighi, David Harvey, Joaquim Hirsch, Bob Jessop, François Chesnais, Samuel Bowles e David Kotz. Por outro lado, como será mostrado ao longo do artigo, a AR deixou de desenvolver e aprofundar a análise de "O capital", de Marx. Além disso, os regulacionistas consideram que alguns diagnósticos marxistas para problemas econômicos, como o subconsumo, o imperialismo e a queda da taxa de lucro são relevantes, mas não são explicações universais, são historicamente situadas (Aglietta, 1979; Coriat, 1994a; Boyer, 2004, 2015). Do ponto de vista de autores marxistas, os regulacionistas são criticados, como será mostrado mais à frente, devido a algumas insuficiências teóricas e problemas nas análises históricas e de conjuntura.

(20) Aglietta (1994) afastou-se das ideias regulacionistas e voltou sua análise a uma relação social específica, a relação monetária, escrevendo diversos livros sobre a moeda e sobre as crises financeiras. 
(Chavance, 2002). O terceiro desenvolvimento foi o diálogo com outras abordagens da economia, como as diferentes linhas do institucionalismo (Villeval, 2002) ${ }^{21}$ e a abordagem neoschumpeteriana (Coriat, Dosi, 2000, 2002) ${ }^{22}$. Por fim, um último daquela coletânea que deve ser destacado é que diversas obras regulacionistas de segunda geração procuraram aprofundar as contribuições da escola acerca dos temas clássicos (como o fordismo) e os conceitos básicos da escola, além de procurar possíveis sucessores do fordismo. Apenas esses últimos temas serão tratados aqui.

Os conceitos principais da escola são os conceitos de formas institucionais, modo de regulação e regime de acumulação, além da tipologia das $\operatorname{crises}^{23}$. A noção de formas institucionais deriva da diferente maneira na qual as relações sociais fundamentais do modo de produção capitalista aparecem, ao longo da história. Com base em Marx, os regulacionistas identificam as três relações sociais mais importantes do capitalismo como a relação salarial, a moeda e a concorrência. Essas relações codificam as três formas institucionais principais: a configuração da relação salarial, a forma da restrição monetária e a forma da concorrência (Boyer, 1990, p. 73-79). Entretanto, tais formas institucionais não resultam, para os regulacionistas, da simples lógica da economia capitalista, mas dependem também da relação entre atores sociais e políticos, além do próprio ambiente mundial no qual determinada economia está inserida. Por isso, diferentemente da análise mais abstrata que Marx teria realizado em "O Capital", os regulacionistas enfatizam outras duas formas institucionais, o tipo de inserção internacional e a forma do Estado.

A definição destas três formas institucionais leva-nos, obrigatoriamente, a refletir sobre o espaço em que elas operam: essencialmente o espaço do Estado-Nação. De um lado, a moeda nacional organiza um desnivelamento entre circulação interna e externa (...). De outro lado, a forma da relação salarial resulta de compromissos, de fato ou

(21) Villeval (2002) considera que a escola da regulação se aproxima do institucionalismo original e deveria aprofundar o diálogo com a última abordagem. Por seu turno, o diálogo com abordagens como a escola austríaca, a escola das convenções e a nova economia institucional seria menos profícuo, em virtude do individualismo metodológico, da formalização e da ênfase na eficiência econômica presentes nas últimas abordagens. Seguindo a mesma linha de Villeval (2002), Baslé (2002) argumenta que a escola da regulação deveria retornar a algumas fontes institucionalistas originais, como Commons, Mitchell e Veblen, pois os mesmos anteciparam muitas das contribuições regulacionistas, como, por exemplo, as teorias sobre a relação capital-trabalho ou sobre a moeda. Tanto Villeval quanto Baslé reconhecem que há pouco diálogo entre os regulacionistas e as demais correntes citadas.

(22) Coriat e Dosi $(2000,2002)$ reconhecem similaridades e complementaridades entre a abordagem regulacionista, que é elaborada de "cima para baixo" ("top-down") e a abordagem evolucionária neoschumpeteriana, que é elaborada de "baixo para cima" ("bottom-up") e argumentam que uma comparação mais sistemática entre as duas abordagens poderia ser "mutuamente enriquecedora". Desse modo, seria possível o desenvolvimento conjunto de conceitos que são relevantes para ambas as escolas, como os conceitos de rotinas e de instituições, que podem servir de pontes entre diversos âmbitos de análise, que abrangeriam desde a microeconomia até a história de longa duração, passando pela análise dos agregados econômicos e da dinâmica macroeconômica. Além da complementaridade, os autores sublinham algumas diferenças entre as teorias. Entre as discrepâncias observadas estariam o nível de análise menos abstrato e mais focado na história, por parte dos regulacionistas, assim como a utilização da firma fordista como um tipo de agente representativo, procedimento não adotado pelos evolucionários.

(23) A apresentação dos conceitos básicos da escola manteve a mesma estrutura desde meados dos anos 1980 até recentemente (Coriat, 1994a; Théret, 1998; Boyer, 1990, 2004, 2015). 
institucionalizados, realizados no interior de alianças de classes ligadas à história nacional de cada país. Finalmente, as formas do Estado originam-se, historicamente, num espaço social bem delimitado, definido pela gestão da moeda e pelos componentes mais importantes da relação salarial (Boyer, 1990, p. 76).

São justamente essas cinco formas institucionais que delimitam o conceito de modo de regulação, que se refere ao funcionamento conjunto do sistema econômico em determinado tempo e espaço. Desse modo, os conceitos básicos da AR continuaram sendo utilizados para realizar uma mediação (uma análise intermediária) entre os conceitos fundamentais de Marx (que a abordagem regulacionista menciona, mas não mais procura desenvolver) e a análise empírica ${ }^{24}$.

Coriat (1994a, p. 8) identifica duas definições de regime de acumulação. A primeira se refere à compatibilização entre os dois departamentos da economia, seguindo a elaboração de Marx no livro II de "O capital". A segunda acepção de um regime de acumulação é a forma na qual se obtém, de dividem e se difundem os ganhos de produtividade. Ambas as caracterizações já estavam presentes no primeiro livro de Aglietta, mas só a segunda prevaleceu nos textos regulacionistas. Théret (1998, p. 12), por exemplo, diferencia os regimes de acumulação "segundo a natureza e a intensidade das transformações técnicas, o volume e a composição da demanda, o tipo de modo de vida assalariado".

Por fim, os autores elaboram uma tipologia das crises econômicas. Um primeiro tipo de crise é a perturbação externa, causada por um choque exógeno e corrigida sem uma mudança estrutural do sistema econômico. O segundo tipo é a crise cíclica, endógena ao capitalismo, mas superada novamente sem mudanças estruturais. A terceira forma da crise é aquela que rompe o funcionamento das instituições em um determinado período ou torna inviável o padrão de acumulação vigente. Esse é o tipo de crise estrutural, que provoca a mudança nas etapas do capitalismo. Um último tipo possível de crise é a ruptura das relações sociais capitalistas, a crise do próprio modo de produção (Boyer, 1990, p. 87-99; Théret, 1998).

Depois de apresentadas as definições das categorias básicas da escola nos anos 1980 e 1990, é importante investigar os principais resultados teóricos apresentados pela abordagem da regulação: a periodização do capitalismo com base no conceito de fordismo e da sua crise, assim como a possibilidade de emergência de um regime de acumulação que supere a crise do fordismo.

Coriat (1994a, p. 9-11) ilustra, de maneira sucinta, a utilização do arcabouço teórico regulacionista na explicação das origens e da crise do fordismo. A origem seria explicada, em

(24) Em textos mais recentes, Boyer (2004, p. 9; 2015, p. 17) argumenta que as pesquisas institucionalistas contemporâneas consideram uma grande variedade de instituições: "normas, valores, convenções, regras legais, organizações, redes, Estados, etc." E indica que o projeto teórico da escola da regulação, partir dos conceitos fundamentais da economia política e daí derivar diferentes formas institucionais, pode ser capaz de "encontrar bases mais sólidas para uma economia institucional". 
poucas palavras, pela sequência "Taylor, Ford, Keynes", ou, de maneira mais precisa, por uma longa série de mutações, tanto no sistema produtivo quanto nas convenções coletivas, que incluiriam a gestão estatal da força de trabalho e da moeda, em um contexto de abertura econômica internacional que não comprometeria a independência das políticas macroeconômicas. Em outros termos, tais instituições permitiriam a obtenção dos ganhos de produtividade e a divisão dos mesmos entre lucros e salários. O fordismo, e por consequência o keynesianismo, teriam entrado em crise com a diminuição dos ganhos de produtividade.

No livro "Miragens e milagres", Lipietz retoma a concepção do fordismo entendido como a conjunção de um regime de acumulação intensiva com um modo de regulação monopolista: “Após a Segunda Guerra Mundial, o regime de acumulação intensiva, centrado no consumo em massa, pôde se generalizar justamente porque um novo modo de regulação, monopolista, havia incorporado a priori na determinação dos salários e dos lucros nominais, um crescimento do consumo popular em proporção aos ganhos de produtividade" (Lipietz, 1988, p. 50).

No âmbito do modo de regulação, as principais formas institucionais seriam: 1) uma relação salarial marcada por convênios coletivos, salário mínimo crescente, previdência social e outras formas de salário indireto; 2) a gestão da moeda marcada pelo dinheiro fiduciário e pela generalização dos empréstimos bancários para as firmas e famílias; 3) formas de governo do tipo Estado-Providência e que adotam políticas econômicas keynesianas; 4) no plano internacional, predominaria a hegemonia americana, já que os Estados Unidos eram o país com maior parque industrial e com maior domínio tecnológico. Além disso, os EUA financiaram os planos Marshall e MacArthur e controlava instituições como GATT, FMI e OCDE. As empresas americanas eram as principais multinacionais, investindo em diversas áreas do mundo (Lipietz, 1988, p. 52-56) ${ }^{25}$.

Nesta obra também aparece uma descrição da crise do fordismo. Segundo o autor, a crise teria começado com uma desaceleração geral dos ganhos de produtividade. Em seguida teria ocorrido uma compressão dos lucros (profit squeeze) decorrente da persistência dos aumentos salariais. Como consequência, esse processo alimentaria maior inflação e menor investimento, o que ampliaria o desemprego. Por sua vez, os gastos sociais do Estado teriam crescido e evitado uma recessão maior, mas não a estagnação. Além disso, os EUA teriam perdido competitividade para a Europa e o Japão e força militar, devido a derrotas no Vietnã e no Oriente Médio (Lipietz, 1988, p. 56-61).

(25) Uma das maiores evoluções dos textos de segunda geração vis-à-vis os trabalhos fundadores da escola, é a busca da superação do determinismo econômico. Lipietz (1988, p. 31) e Coriat (1994a, p. 8-9), por exemplo, procuram se resguardar do determinismo ao afirmar que tanto o modo de regulação quanto o regime de acumulação são "achados da história", que dependem da própria ação conflituosa dos homens para sua construção. Lipietz (1988, p. 31-33) afirma que deve-se evitar o "intencionalismo" e o "funcionalismo" implícitos na explicação da origem das instituições baseada na necessidade de se estabilizar um regime de acumulação. Tal estabilização seria acidental. O autor cita, para exemplificar tal raciocínio, que o Estado de bem-estar social não foi criado para estabilizar o fordismo. 
Em um texto apresentado em uma conferência realizada no Brasil em 1998, Robert Boyer sintetiza de modo muito preciso a concepção dos anos 1990 da escola da regulação acerca das origens do fordismo, a "era de ouro do capitalismo". Na longa citação a seguir, fica claro que o fordismo não é resultado apenas de mudanças tecnológicas e organizacionais do capitalismo, como nas versões originais (e deterministas) da escola, mas resultado de uma série de compromissos institucionalizados:

O excepcional dinamismo e a notável estabilidade do crescimento, observados depois de 1950 nos Estados Unidos, na Europa e no Japão, tiveram por origem as obrigações impostas pela evolução social e política do pós-guerra sob a forma de acumulação do capital. Pela primeira vez, na sua maioria, os assalariados foram inseridos política (graças à difusão do sufrágio universal e da democracia) e economicamente nas sociedades contemporâneas: a produção de massa floresceu devido a um compromisso entre capital e trabalho, sem dúvida diferente, segundo os países, mas que tinha por propriedade comum marcar a inserção a título vitalício do conjunto dos assalariados e não mais simplesmente o do capital, como afirmava na época a teoria do capitalismo monopolista de Estado. Esse regime institucional fordista, edificado sobre a Pax americana, a aceitação dos métodos modernos de produção, a concorrência moderada, uma moeda de crédito pura e um Estado deliberadamente intervencionista, teve, durante quase um quarto de século, a vantagem de atenuar consideravelmente os desequilíbrios da acumulação, ao mesmo tempo em que assegurava a permanência de um apoio às alianças governamentais que finalmente se tornaram muito estáveis. Mas aos "trinta gloriosos" (1946-1976) sucederam-se os "vinte dolorosos" (1977-1997) e a explicação dessa oscilação está no cerne do projeto regulacionista (Boyer, 1998, p. 195-196).

Entretanto, mantendo o foco inicial da escola na crise do fordismo como crise dos métodos de produção, o autor identifica a derrocada do regime de acumulação como resultante da diminuição dos ganhos de produtividade nos Estados Unidos. A decadência dos métodos produtivos que foram muito bem-sucedidos no pós-guerra seria responsável pelo retorno de um regime de acumulação extensiva:

Nos EUA essa situação [a crise do fordismo] é mais grave, o método fordista e a substituição do capital pelo trabalho tropeçam numa interminável diminuição da produtividade há mais de duas décadas. Na América do Norte, a acumulação não é mais intensiva, centrada no consumo de massa, mas extensiva e construída sobre a diferenciação dos modos de vida e o reforço das desigualdades (Boyer, 1998, p. 196$197)^{26}$.

Os textos regulacionistas das décadas de 1980 e 1990 que tratam do fordismo e sua crise argumentam que essas décadas seriam um período de continuação da crise do fordismo. De acordo com Coriat, por exemplo, a crise do fordismo não foi solucionada nos anos 1980 ,

(26) A passagem da acumulação intensiva para a acumulação extensiva e o aprofundamento das desigualdades é presente em outros textos de Boyer, como no trabalho publicado juntamente com Juillard (2002, p. 378) e em livros mais recentes, mencionados a seguir (Boyer, 2004, 2015). 
período no qual os regulacionistas foram procurar por novas regularidades, tanto no nível micro ${ }^{27}$ quanto no nível macro, que pudessem garantir um novo regime de acumulação: "Em outras palavras, pode-se dizer que os anos 1980, que viram o aprofundamento do questionamento das regularidades fordistas, foram também, sobretudo, de pesquisa, ainda que balbuciante e caótica, da passagem a esses regimes de crescimento pós-fordistas" (Coriat, 1994a, p. 12) $)^{28}$.

No caso francês e europeu, de acordo com Coriat (2002), o bloco econômico continental estaria restringindo as políticas monetárias e fiscais dos países. Na década de 1980, a Europa teria sofrido com as políticas de austeridade. O governo francês teria implementado, nos anos 1980 e no começo da década de 1990, uma política de "desinflação competitiva", que se mostraria incapaz de restaurar a competitividade das pequenas e médias empresas. Ainda segundo Coriat (2002), todas essas políticas, associadas às ondas de privatização e da "balkanização" 29 das relações salariais, estariam contribuindo para a dissolução do modelo fordista, que não teria sido substituído por nenhum outro modelo capaz de garantir ciclos virtuosos de crescimento e prosperidade.

Do ponto de vista dos conceitos da AR, as décadas de 1980 e 1990 consolidam a inflexão da escola em direção a uma abordagem mais historicista e menos teórica do capitalismo. Os autores não mais procuram desenvolver os insights de Marx. Os trabalhos dessas décadas também são marcados pela tentativa de eliminação do determinismo e pela busca de maior rigor conceitual e analítico (Lipietz, 1988; Coriat, 1994a; Boyer, 1990; Boyer, Saillard, 2002). Apesar disso, os regulacionistas enfatizam, de modo reducionista, a diminuição do crescimento da produtividade como o fator principal que levou à crise do fordismo (Lipietz, 1988; Coriat, 1994a; Boyer, 1998; Boyer, Juillard, 2002). Além disso, várias obras foram dedicadas ao estudo dos novos padrões de crescimento sendo implantados (Coriat, 2002; Boyer, 1998; Boyer, Juillard, 2002). Essas últimas obras, apesar de reconhecerem a importância de outros modelos produtivos, diversos do fordismo, enfatizam o conceito de pós-fordismo. Os diferentes autores advogam que não havia, nos anos $1980 \mathrm{e}$ 1990, um modelo produtivo já estabelecido nos países centrais, após a crise do padrão de crescimento do pós-guerra.

(27) Coriat é uma das principais referências no estudo dos processos de trabalho. Publicou um estudo detalhado do modelo japonês de produção, o toyotismo, modelo que superou várias das limitações do fordismo, e foi adotado por diversos setores, no Japão. O toyotismo, que não será descrito com detalhes no presente trabalho, começou a ser implantado nas fábricas da Toyota pelo engenheiro Ohno, no contexto do pós-guerra. Como o Japão não possuía um mercado interno muito forte, Ohno optou por realizar algumas inovações organizacionais, estabelecendo o padrão de organização do trabalho que viria ser chamado de ohnismo, toyotismo, modelo japonês, ou de produção enxuta. Algumas das inovações desse modelo seriam o método just-intime, o kan-ban, a subcontratação, a maior flexibilidade das linhas de montagem e dos processos de produção (Coriat, 1994b).

(28) "En d'autres termes on dira que les années 1980 qui voient s'approfondir la remise en cause des régularités fordiennes sont aussi et surtout celles de la recherche encore balbutiante et chaotique du passage à des régimes de croissance post-fordiens" (Coriat, 1994a, p. 12).

(29) Degradação das condições de trabalho, dos níveis salariais e dos índices de ocupação. 


\section{A abordagem da regulação e o capitalismo contemporâneo}

Depois do ano 2000, a escola da regulação procurou se aprofundar em três eixos principais, que serão descritos a seguir: a análise das instituições e da mudança institucional; os diferentes níveis de análise (microeconômico, regional, nacional, internacional e mundial) e as variedades do capitalismo; as crises europeia e estadunidense contemporâneas e os novos modelos de capitalismo. No período recente, alguns autores (Jessop, Sum, 2006, 2016; Chanteau et al., 2016; Boyer, 2004, 2015) $)^{30}$ procuraram realizar uma síntese do desenvolvimento da escola da regulação, além de apresentar o que consideram o estado das artes da abordagem.

Do ponto de vista teórico, houve a continuidade do diálogo com as correntes institucionalistas, neoschumpeteriana e pós-keynesiana. Exemplos desses diálogos estão, respectivamente, na análise da inércia institucional e da mudança institucional, dos sistemas de inovação e do capitalismo financeiro (Boyer, 2015; Chanteau et al., 2016; Jessop, Sum, 2016).

Em relação ao conceito de instituições, uma das preocupações centrais do líder da escola, Robert Boyer (2015, p. 109, p. 124-132) é a de apresentar os "fundamentos macroeconômicos e institucionais para uma microeconomia pertinente". As formas institucionais constituiriam um "nível intermediário" entre os níveis macro e micro. Um dos aspectos mais relevantes para a explicação da mudança institucional é a política. A escola francesa da regulação não aceita a visão comum de que a política e a economia são separadas. Boyer (2015), retornando à Gramsci, procura analisar, por exemplo, a formação e a dissolução de blocos hegemônicos que garantiam o funcionamento do fordismo e também do capitalismo financeirizado. No primeiro regime de acumulação os trabalhadores e os empresários teriam feito parte do bloco hegemônico, enquanto que, com a internacionalização e a financeirização da economia, os trabalhadores foram, progressivamente, sendo deixados de lado. A introdução da política, assim como da ecologia, na análise regulacionista, possibilita que se vislumbrem diferentes temporalidades nas quais os problemas políticos, econômicos e ecológicos são tratados (Boyer, 2004, 2015; Lipietz, 2015; Jessop, Sum, 2006, 2016; Chanteau et al., 2016).

O método regulacionista foi aplicado em diferentes âmbitos de investigação (microeconômico, regional, nacional, internacional e mundial). A escola se afastou da preocupação excessiva com o fordismo e passou a analisar diferentes modelos produtivos, ao nível das firmas (Boyer; Freyssenet, 2000) e também a considerar a diversidade dos capitalismos (Amable, 2003; Boyer, 2004, 2011; Lipietz, 2001, 2015). Alguns dos focos

principais de análise são os Estados Unidos, a China, a América Latina e a União

(30) O livro de Boyer (2015) "Économie politique des capitalismes: théorie de la régulation et des crises" reedita e atualiza o livro "Théorie de la régulation: les fondamentaux" (BOYER, 2004). 
Europeia $^{31}$. Boyer (2015) também se preocupou com o papel que as ideias econômicas e sociais - tais como o liberalismo, a teoria novo clássica e o monetarismo - desempenham na construção de instituições e na formação de padrões de política econômica, como por exemplo as políticas de austeridade ${ }^{32}$.

Os regulacionistas, no início dos anos 2000, deram continuidade às linhas de pesquisa dos anos 1990, procurando os possíveis sucessores do fordismo. Entre os sucessores do fordismo, um regime de crescimento estaria prevalecendo nos Estados Unidos, até a crise de 2007: o regime de acumulação liderado pelas finanças. Na sequência desta parte do texto serão apresentadas as concepções de Boyer, Lipietz, Lordon e outros autores regulacionistas, acerca desse regime e de sua crise.

No ano 2000, Robert Boyer publicou um artigo que marca o início da ênfase da escola da regulação no estudo da viabilidade do regime de crescimento liderado pelas finanças. Tal regime poderia vir a ser o sucessor do fordismo no Estados Unidos e em alguns outros países, especialmente a Inglaterra. Em um texto publicado no ano seguinte, Lipietz (2001, p. 17), argumenta que o modelo do fordismo, dos países centrais, que prevaleceu na era de ouro do capitalismo, entrou em crise nos anos 1970 e deu origem a um período de experimentação. No caso específico dos Estados Unidos, mas também de outros países, o modelo que estaria triunfando seria o liberal-produtivista, neo-taylorista ou flexível.

Do ponto de vista macroeconômico (ou do regime de acumulação), devido à diminuição da proporção dos salários na renda nacional, os volumes de produção e de emprego nos países que adotam o modelo liberal-produtivista estariam muito mais instáveis, pois são sujeitos ao "espírito animal" das decisões dos capitalistas. Outras duas características do liberal-produtivismo, que contribuiriam para os efeitos negativos em termos de nível de atividade, de distribuição de renda e de geração de emprego, seriam a globalização e a financeirização. Um dos efeitos colaterais do sistema, causado pela insuficiência de demanda agregada, seria a ocorrência de elevados déficits fiscais. Por fim, o autor termina seu texto argumentando que a situação econômica dos Estados Unidos, apesar do elevado crescimento dos anos 1990, não se sustentaria por muito tempo e o país passaria por crises provocadas pelo estouro de bolhas financeiras (Lipietz, 2001, p. 29-35).

Nos anos seguintes, uma das linhas de pesquisa seguidas por Boyer continuou sendo a busca por possíveis sucessores do fordismo. Em termos esquemáticos, teria ocorrido a sucessão de quatro modos de desenvolvimento (junção de um regime de acumulação com um modo de regulação) ao longo da história do capitalismo, sendo que um deles teria se mostrado inviável (Boyer, 2004, p. 56-61; 2015, p. 62-68):

(31) A escola da regulação é criticada por não compreender a dinâmica da economia mundial como produto de relações sociais conflituosas que se articulam tanto nos planos nacionais quanto no âmbito mundial (Amin, 1994; Medeiros, 1998). Essa falha ainda ocorre nos dias atuais. A combinação das economias chinesa, estadunidense, latino-americana e europeia aparece mais como um "acaso" do que como o resultado lógico da evolução conjunta desses quatro sistemas econômicos (Boyer 2015, p. 276-277).

(32) Todavia, a escola da regulação trata o predomínio de visões ortodoxas da economia e as políticas de austeridade de modo idealista, respectivamente como "consensos acadêmicos" equivocados e como "erros de política econômica" e não como faces de um projeto político de diminuição do poder da classe operária e dos direitos sociais. 
1) acumulação extensiva com regulação concorrencial, característica da segunda metade do século XIX, período de industrialização crescente, que substitui os setores tradicionais pela manufatura. Tal substituição é um tipo de acumulação extensiva. A demanda é puxada pelo consumo das elites, já que os salários são determinados concorrencialmente;

2) acumulação intensiva sem consumo em massa, modo de desenvolvimento instável dinamicamente. A ciência e a técnica foram mobilizadas para racionalizar os métodos de produção. Os salários não acompanham os ganhos de produtividade. Crises de subconsumo acabaram por mostrar a inviabilidade do padrão de crescimento;

3) acumulação intensiva com consumo em massa. Fundada com a institucionalização da participação dos salários nos ganhos de produtividade. A aplicação da ciência e da tecnologia é intensiva. O Estado garante investimentos públicos, estabilidade do crescimento e do emprego e direitos sociais. Foi o modo de desenvolvimento fordista;

4) acumulação extensiva com aprofundamento das desigualdades, regime que sucedeu o fordismo nos Estados Unidos. A contestação do fordismo levou ao retorno a um padrão de crescimento com baixos ganhos de produtividade, um regime de acumulação extensiva. A relação salarial fordista foi destruída, houve maior taxa de desemprego, menores níveis salariais e de proteção social. Aprofundou-se a concorrência internacional.

A acumulação extensiva com aprofundamento das desigualdades, modo de desenvolvimento que estaria sucedendo o fordismo nos EUA, poderia ser acompanhada por um modo de regulação dominado pelas finanças: "Já foi evocada a possibilidade de um modo de regulação dominado pelas finanças de mercado como possível sucessor da regulação monopolista" (Boyer, 2004, p. 91; 2015, p. 95-97) ${ }^{33}$. O Quadro 1, a seguir, resume os principais regimes de acumulação identificados pela AR.

Quadro 1

Principais regimes de acumulação da história do capitalismo

\begin{tabular}{l|c|c}
\hline Acumulação & Extensiva & Intensiva \\
\hline Podo de consumo & $\begin{array}{c}\text { Economia inglesa dos séculos } \\
\text { XVIII e XIX. Possibilidade de } \\
\text { crises cíclicas provocadas por } \\
\text { excesso ou falta de investimento }\end{array}$ & $\begin{array}{c}\text { Economia americana do final do } \\
\text { século XIX e início do século XX. } \\
\text { Possibilidade de crises de } \\
\text { superprodução e subconsumo } \\
\text { (como a crise de 1929) }\end{array}$ \\
\hline \multirow{3}{*}{ Muito integrado ao capitalismo } & $\begin{array}{c}\text { Economias americana e inglesa do } \\
\text { final do século XX e início do } \\
\text { século XXI. O consumo é } \\
\text { estimulado pelo endividamento ou } \\
\text { por bolhas de ativos. Possibilidade } \\
\text { de crises financeiras }\end{array}$ & $\begin{array}{c}\text { Fordismo. Teria predominado nas } \\
\text { economias da OCDE entre 1945- } \\
\text { 1973. Caracteriza-se por produção e } \\
\text { consumo em massa. Possibilidade } \\
\text { de crises inflacionárias ou de } \\
\text { estagflação }\end{array}$ \\
\hline
\end{tabular}

Fonte: Adaptado a partir de Boyer (2015, p. 62).

(33) "La possibilité d'un mode de régulation dominé par la finance de marché a déjà été évoquée, comme possible successeur de la régulation monopoliste" (Boyer, 2004a, p. 91; 2015, p. 95-97). 
Nesse possível sucessor do fordismo, a rentabilidade das finanças substituiria o salário como principal fonte do aumento da demanda: "Mutadis mutandis, este regime é então um sucessor potencial do modelo de desenvolvimento fordista, com a dinâmica da bolsa substituindo o salário como fonte de crescimento cumulativo" (Boyer, 2004, p. 95; 2015, p. 99) ${ }^{34}$. Para que tal modelo apresente um ciclo virtuoso, bastaria que a rentabilidade da bolsa estimulasse o consumo, que por sua vez estimularia o investimento:

Pode, assim, ter início um círculo virtuoso: um aumento da rentabilidade financeira estimula a bolsa de valores, que provocaria um crescimento do consumo, que por sua vez estimula o investimento e compensa o efeito, a priori negativo, de elevação dos padrões de rentabilidade. O nível de produção é então, o resultado da avaliação financeira, o que inverte a relação entre a economia real e a esfera financeira que prevalecia sob o fordismo (Boyer, 2004, p. 93; 2015, p. 97-99) ${ }^{35}$.

Outro autor que se debruçou sobre o tema, Frédéric Lordon, publicou em 2008 um texto provocante, na forma de epílogo do livro "Jusqu'à quand? L'éternel retour de la crise financière", escrito no período do epicentro da crise americana. Argumenta que a crise é diferente dos demais colapsos financeiros recentes, pois pode ser a última crise da atual configuração do capitalismo, marcada pela financeirização e pela desregulamentação da economia como um todo.

O ambiente internacional, marcado pela liberalização comercial e financeira, estaria fazendo um nivelamento por baixo dos padrões salariais, além de piorar as condições de trabalho, de estabilidade no emprego e de oferta de programas sociais. Tal fato estaria ocorrendo inclusive na França, mesmo nos períodos de governos que se proclamam de esquerda. Como resultado, há uma redistribuição da renda em favor dos lucros. A queda dos salários deprime a demanda agregada, que acabaria sendo sustentada pela ampliação do endividamento e por déficits fiscais (Lordon, 2008). Em contraste com as ideologias liberais, argumenta que, no caso da França, seriam justamente a rigidez do mercado de trabalho e o Estado muito avantajado (com suas políticas anticíclicas), que impediriam a ocorrência de uma grave depressão. Depois de seguidos colapsos financeiros, a crise iniciada em 2008 fez o autor levantar a hipótese de que se trata de grande crise, que determinaria o fim de uma etapa do capitalismo.

Mais recentemente, Boyer (2015, p. 323-324) afirmou que "[a] longa busca por um sucessor para o fordismo pelas velhas economias industriais não rendeu os frutos

(34) "Mutadis mutandis, ce régime est donc bien un successeur potentiel du modèle de développement fordiste, la dynamique boursière remplaçant le salaire comme source de croissance cumulative" (Boyer, 2004a, p. 95; 2015, p. 99).

(35) "Peut ainsi s'amorcer un cercle vertueux: un relèvement de la rentabilité financière stimule la Bourse, ce qui motive un accroissement de la consommation qui elle-même stimule l'investissement et compense l'effet a priori négatif du relèvement de normes de rendement. Le niveau de la production est donc la conséquence de l'évaluation financière, ce qui renverse les relations entre sphère réelle et sphère financière qui prévalaient sous le fordisme" (Boyer, 2004a, p. 93; 2015, p. 9799). 
esperados"36 e que o "neoliberalismo se revelou incapaz de refundar um regime de acumulação viável" ${ }^{37}$. Outros autores ligados à escola da regulação procuraram problematizar a existência de um padrão de crescimento liderado pelas finanças. Um desses autores, Mickaël Clévenot publicou, no ano de 2008, um artigo no periódico ligado à escola, Revue de la Régulation, que procura resolver a tensão, no seio da literatura regulacionista, entre a viabilidade ou a inviabilidade de um regime de acumulação liderado pelas finanças. Procurando compatibilizar diferentes visões acerca do capitalismo financeiro, o autor, por um lado, identifica no capitalismo americano contemporâneo uma coerência institucional. Por outro lado, tal arcabouço institucional seria incapaz de sustentar um crescimento que não seja de curto prazo (Clévenot, 2008, p. 9-12). Para superar essa contradição entre um conceito de um regime inviável a longo prazo e as evidências de um regime viável a curto e médios prazos, Clévenot $(2008$, p. 2) propõe que há um regime de crescimento puxado pelas finanças: "instável, excludente e sem capacidade de reprodução a longo prazo", apesar de permitir regular as "pequenas crises". O conceito de regime de crescimento, portanto, não exigiria a estabilidade econômica e social implícita no conceito de regime de acumulação.

Outro pesquisador ligado à escola francesa da regulação, Thomas Lamarche, em um texto que procura refutar críticas dirigidas à corrente, reconhece que a $\mathrm{AR}$ teve dificuldades em compreender e nomear o regime de acumulação dos anos $1990^{38}$. "A dificuldade enfrentada pela teoria da regulação provém do caráter instável do regime (com a questão de saber se podemos definir um regime com tão pouca estabilidade) e do fato de que ele não se baseia em um regime de acumulação comum a um conjunto de países, ao contrário da acumulação intensiva, que o precedeu" (Lamarche, 2012, p. 4) ${ }^{39}$. O autor parece concordar com a posição de Clévenot (2008), que afirma que o padrão de crescimento liderado pelas finanças não pode ser caracterizado como um regime de acumulação, mas sim como um "regime de crescimento", que seria "impossível de se reproduzir" e idiossincrático aos Estados Unidos, não sendo facilmente replicável (Lamarche, 2012, p. 5).

Após o estouro da bolha das hipotecas subprime, os autores regulacionistas aprofundaram a investigação do padrão de crescimento americano das últimas décadas e adotaram a visão de que se tratava de um regime liderado pelas finanças, segundo Boyer (2011, 2015) ou como liberal-produtivista, de acordo com Lipietz (2015). A crise de 2008 marcaria o fim desse regime e o início de um novo período de experimentação (Boyer, 2015; Lipietz, 2015; Lordon, 2008).

(36) 'La longue quête d'un successeur au fordisme par les économies de vieille industrialisation n'a pas donné les fruits attendus" (Boyer, 2015, p. 323).

(37) “(...) le néolibéralisme s'est révélé incapable de refonder un régime d'accumulation viable” (Boyer, 2015, p. 324).

(38) Outros autores da escola reconhecem a dificuldade em definir os modos de regulação dos anos 1980 em diante (Boyer, 2015; Chanteau et al., 2016).

(39) "La difficulté à laquelle se trouve confronté la théorie de la régulation provient du caractère instable du régime (avec la question de savoir si l'on peut définir un régime avec si peu de stabilité) et du fait qu'il ne repose pas sur un régime de accumulation commun à un ensemble de pays, à la différence de l'accumulation intensive qui précède" (Lamarche, 2012, p. 4). 


\section{Críticas dirigidas à escola da regulação}

$\mathrm{Na}$ década de 1970 e no início dos anos 1980, os regulacionistas procuraram desenvolver uma abordagem que fizesse uma mediação entre os conceitos de Marx e a realidade empírica (Aglietta, 1979; Lipietz, 1983). Nas décadas de 1980 e 1990, a escola da regulação se afastou do objetivo fundador e procurou se consolidar como desenvolvedora de uma "macroeconomia institucional e histórica" (Boyer, 2004, p. 104-107; Billaudot, 2001). Mais recentemente, a abordagem continuou aprofundando o projeto das décadas de 1980 e 1990 e procurou desenvolver um tipo de "institucionalismo histórico" e um nível intermediário de análise entre o macro e o micro (às vezes chamado de mesoeconômico) (Boyer, 2015; Chanteau et al., 2016; Jessop, Sum, 2016).

Alguns intérpretes e alguns adeptos da corrente argumentaram que, ao se distanciar da teoria básica de Marx $^{40}$, os autores da escola ficaram sem uma visão geral do capitalismo $^{41}$ (Vidal, 2001; Mavroudeas, 2006; Jessop, Sum, 2006, 2016; Boyer, 2004a; Lamarche, 2012, Chanteau et al., 2016). Segundo alguns desses intérpretes, isso teria provocado algum nível de dificuldade de compreender o capitalismo contemporâneo (Mavroudeas, 2006; Jessop, Sum, 2006, 2016).

O diagnóstico aqui realizado contraria a concepção de que a AR abandonou uma visão geral do capitalismo e aponta que, quando os teóricos da escola tentaram abrir mão de uma concepção geral do funcionamento do sistema econômico, eles não conseguiram fazê-lo. E acabaram adotando, seja de modo explícito, seja de maneira implícita, uma compreensão pré-teórica sobre o modo de produção capitalista, inadequada e inconsistente com o projeto inicial da escola. Essa concepção pré-teórica tem dois componentes principais: a visão de que as mudanças históricas do capitalismo são explicadas por transformações no crescimento da produtividade e a visão de que o funcionamento normal do capitalismo contemporâneo pressupõe crescimento elevado e estável, baseado em compromissos institucionalizados ${ }^{42}$. $\mathrm{O}$ Quadro 2, a seguir, resume a evolução da escola.

(40) Depois do ano 2000, Boyer (2004, p. 4, 2015, p. 6) continuou argumentando que o projeto teórico da AR se inscreve na tradição do pensamento de Marx, "mas pretende alterar e prolongar a análise de 'O capital', tanto à luz dos métodos modernos dos economistas quanto graças aos ensinamentos derivados das transformações do capitalismo desde o final do século XIX" ("La théorie de la régulation s'inscrit das cette tradition théorique, mais elle entend amender et prolonger les analyses du Capital, tant à la lumière des méthodes modernes de l'économiste que grâce aux enseignements issus des transformations du capitalisme depuis la fin du XIX siècle"). Entretanto, diferentemente das obras iniciais da corrente (Aglietta, 1979; Lipietz, 1983), nas últimas décadas a escola não "altera e aprofunda" a análise de "O capital" e se aproximou mais do que o próprio Boyer (2015, p. 323) chama de "institucionalismo histórico".

(41) "Em vez de uma teoria geral, a teoria da regulação é uma teoria fundada na compreensão da variabilidade histórica do real. Isso constitui uma grande diferença em relação à produção de uma teoria geral que visa estabelecer uma explicação universal" ("Plutôt qu'une théorie générale, la théorie de la régulation est une théorie fondée sur la variabilité historique raisonnée du réel. Cela forme une différence majeure avec la production d'une théorie générale qui vise à fonder une explication de portée universelle") (Lamarche, 2012, p. 5).

(42) Outra crítica, bastante importante, mas que não será tratada adequadamente aqui é o viés nacional da abordagem regulacionista, que subestimaria o caráter transnacional do capitalismo (Amin, 1994; Medeiros, 1998). 
Quadro 2

Evolução dos principais conceitos da escola da regulação

\begin{tabular}{|c|c|c|c|c|}
\hline Período & $\begin{array}{c}\text { Regime de } \\
\text { acumulação }\end{array}$ & Modo de regulação & $\begin{array}{c}\text { Formas } \\
\text { institucionais }\end{array}$ & Problemas teóricos \\
\hline $\begin{array}{l}\text { Trabalhos } \\
\text { fundadores }\end{array}$ & $\begin{array}{l}\text { Esquemas de } \\
\text { reprodução. } \\
\text { Acumulação } \\
\text { extensiva versus } \\
\text { intensiva }\end{array}$ & $\begin{array}{c}\text { Regulação } \\
\text { monopolista do } \\
\text { fordismo substitui a } \\
\text { regulação } \\
\text { concorrencial }\end{array}$ & $\begin{array}{c}\text { Mudança } \\
\text { institucional } \\
\text { provocada pelas } \\
\text { mudanças na } \\
\text { acumulação }\end{array}$ & $\begin{array}{l}\text { Determinismo } \\
\text { tecnológico. } \\
\text { Acumulação } \\
\text { extensiva versus } \\
\text { intensiva }\end{array}$ \\
\hline $\begin{array}{l}\text { Décadas de } \\
1980 \text { e } 1990\end{array}$ & $\begin{array}{c}\text { Dicotomia } \\
\text { acumulação } \\
\text { extensiva versus } \\
\text { intensiva }\end{array}$ & $\begin{array}{l}\text { Busca por pós- } \\
\text { fordismo. } \\
\text { Reconhecimento de } \\
\text { outros modelos } \\
\text { (Japão, América } \\
\text { Latina etc.) }\end{array}$ & $\begin{array}{l}\text { São achados da } \\
\text { história. } \\
\text { Importância dos } \\
\text { compromissos } \\
\text { institucionalizados }\end{array}$ & $\begin{array}{l}\text { Âmbito nacional de } \\
\text { análise. Dificuldade } \\
\text { de compreensão do } \\
\text { capitalismo da } \\
\text { época }\end{array}$ \\
\hline Anos 2000 & $\begin{array}{c}\text { Dicotomia } \\
\text { acumulação } \\
\text { extensiva versus } \\
\text { intensiva; uso } \\
\text { menos formal do } \\
\text { conceito }\end{array}$ & $\begin{array}{l}\text { Variedades de } \\
\text { capitalismo: } \\
\text { financeiro, } \\
\text { socialdemocrata, } \\
\text { chinês, da Zona do } \\
\text { Euro etc. }\end{array}$ & $\begin{array}{c}\text { Mediação entre } \\
\text { macro e micro. } \\
\text { Diálogo com } \\
\text { institucionalistas e } \\
\text { evolucionários. } \\
\text { Importância da } \\
\text { política }\end{array}$ & $\begin{array}{c}\text { Dificuldade de } \\
\text { análise no plano } \\
\text { internacional. } \\
\text { Ausência de } \\
\text { conceitos sobre o } \\
\text { capitalismo causa } \\
\text { idealismo }\end{array}$ \\
\hline
\end{tabular}

Fonte: Elaboração própria.

Alguns críticos apontaram para os sintomas principais associados a esses dois problemas. Um artigo de Clarke e dois artigos de Brenner (um deles em parceria com Glick) questionam a existência histórica de um padrão de crescimento com baixa elevação da produtividade seguido de um padrão de rápido crescimento da mesma. "A ideia de que a acumulação antes da Primeira Guerra Mundial era baseada na produção de mais-valor absoluto parece muito estranha para alguém familiarizado como os rudimentos da história econômica do capitalismo" (Clarke, 1991, p. 113)

Brenner (1999) argumenta que a abordagem da regulação é a principal escola de pensamento que apresenta uma explicação para a crise dos anos 1970 com base na exaustão das tecnologias fordistas e tayloristas. Segundo o autor, essa narrativa da crise seria incapaz de explicar porque países que não se enquadravam no caso típico do fordismo e obtinham elevados ganhos de produtividade, como por exemplo o Japão, também entraram em crise. De fato, a produtividade só teria crescido de modo menos acelerado no mundo como um todo a partir de 1973, sendo causa, e não consequência, da diminuição dos níveis de crescimento.

Por fim, os compromissos institucionalizados, longe de responderem ao regime de acumulação, seriam resultado da correlação de forças das classes sociais. Historicamente,

(43) "The idea that accumulation before the First World War was based on the production of absolute surplus value appears very strange to anyone familiar with the rudiments of the economic history of capitalism" (Clarke, 1991, p. 113). 
enquanto o keynesianismo teria sido uma ideologia que estava associada à resposta do capital e do Estado para as aspirações da classe trabalhadora, o neoliberalismo seria a ideologia que representava a subordinação dos trabalhadores às aspirações do capital. As políticas econômicas neoliberais de transferência de renda, endividamento e aumento dos gastos militares teriam sustentado o crescimento nos anos 1980 (Clarke, 1991, p. 120-129). De acordo com Negri (1994), o próprio capital tem agido de modo a eliminar a "figura mesma do compromisso", a "forma contrato".

O segundo foco importante de insuficiências estaria associado à incapacidade de compreensão do capitalismo das últimas duas décadas. Coutrot (2009), Negri (1994) e Husson (2009) argumentam que a abordagem estaria procurando por um modo de regulação que promova crescimento elevado e estável, garantindo desse modo a coesão social. O capitalismo atual não estaria sendo reconhecido como um capitalismo viável pelos regulacionistas devido ao harmonicismo (a concepção falsa de que um modo de regulação deveria ser estável, coerente e legítimo):

Se o fordismo acabou e o capitalismo não colapsou, é porque ele tem sido capaz de inventar algo novo e um novo modo de regulação foi instituído. Basicamente, os regulacionistas têm esquecido de ser regulacionistas, porque eles têm passado vinte anos explicando que nós estamos "em uma encruzilhada", em vez de estudar o modo de regulação sendo estabelecido diante dos nossos olhos. Ou, levando a tendência ao harmonicismo à sua última conclusão, nós deveríamos reservar o rótulo para as formas boas, estáveis, coerentes e legítimas de regulação (...). Em contrapartida, me parece que é perfeitamente possível estabelecer, de um ponto de vista marxista-regulacionista, se desejado, as coordenadas de um modelo para o funcionamento do capitalismo baseado no crescimento conjunto da taxa de exploração, da taxa de desemprego e da parcela da renda nacional indo para os rentistas (Husson, 2009, p. 185) ${ }^{44}$.

A escola da regulação trata a Crise de 2008 como uma grande crise, que marcaria a transformação das formas institucionais predominantes nos países nos quais predominaria o capitalismo financeiro (como os Estados Unidos e a Inglaterra, por exemplo). E, como nos trabalhos das décadas de 1980 e 1990, reconhece que o futuro não está definido e identifica possíveis tipos de capitalismo que poderiam predominar (economia das Tecnologias de Informação e Comunicação, economia verde, economia do decrescimento, economia do bemestar e economia mista) (Boyer, 2015, p. 308-310). Boyer subestima o poder e a resiliência do capitalismo financeiro, que não parece ter perdido capacidade política após a crise de 2008.

(44) "If Fordism is at an end and capitalism has not collapsed, it is because it has been able to invent something new and a new mode of regulation has been instituted. Basically, the regulationists have forgotten to be regulationists, because they have spent twenty years explaining that we are 'at a crossroads', rather than studying the mode of regulation being established before our very eyes. Or, taking the drift towards harmonicism to its ultimate conclusion, we should reserve the label for good, stable, coherent and legitimate forms of regulation (...) In contrast, it seems to me that it is perfectly possible to set out, from a Marxist-regulationist standpoint if one wishes, the co-ordinates of a model for the functioning of capitalism based on a conjoint increase in the rate of exploitation, the rate of unemployment, and the share of national income going to rentiers" (Husson, 2009, p. 185). 
Pelo contrário, a onda conservadora nas Américas e a persistência das políticas de austeridade na Europa indicam que a hegemonia do capital financeiro está longe do fim.

A AR acertou ao procurar incorporar conceito da filosofia política ao seu corpo teórico. Por exemplo, o retorno às ideias Antônio Gramsci (Boyer, 2015) tem se mostrado proveitoso. A escola francesa da regulação explora, por exemplo, a formação de um bloco hegemônico entre o capital financeiro e o capital industrial e destaca o papel que teorias econômicas ortodoxas, como a teoria novo clássica e o monetarismo, desempenham na formação de consensos que legitimem esse bloco hegemônico. Entretanto, a abordagem falha ao desconsiderar o papel central que a coerção desempenha na manutenção da hegemonia política. Assim, os regulacionistas ignoram que o poder político do capital financeiro e do capital industrial tem se baseado, talvez de forma crescente, no aumento da violência interna aos países, das guerras, da xenofobia e do encarceramento em massa.

A abordagem da regulação acerta ao identificar a pluralidade dos modelos produtivos, dos tipos de capitalismo e ao destacar a importância das instituições e da mudança institucional para compreensão da economia. Porém, a escola falha ao desconsiderar o papel que as tendências de longo prazo do capitalismo desempenham na dinâmica das sociedades contemporâneas. A desindustrialização, a substituição do homem pela máquina, a luta de classes e as catástrofes ecológicas são tendências essenciais para a compreensão do capitalismo atual e futuro.

\section{Comentários finais}

A abordagem francesa da regulação se originou em meados da década de 1970, tendo como objetivo principal compreender as transformações econômicas da época. A corrente foi marcada, desde sua origem, por uma leitura crítica do marxismo e do keynesianismo. A principal discordância dos autores regulacionistas em relação a essas correntes é a incapacidade que teriam de captar as mudanças históricas, as transformações qualitativas do capitalismo. Essa mesma crítica é dirigida à teoria neoclássica.

Vários dos primeiros trabalhos regulacionistas, elaborados na segunda metade dos anos 1970 e no começo da década de 1980, procuraram partir da análise de Marx do modo de produção capitalista e elaborar conceitos menos abstratos que os de Marx, para captar as transformações qualitativas do capitalismo ocorridas no século XX. Essa é a origem do conceito de modo de regulação, elaborado para compreender as transformações institucionais do sistema econômico, modificado para dar conta de absorver (regular) as tensões originárias da generalização de práticas industriais mais produtivas, baseada na extração de mais-valor relativo (o conceito regulacionista de regime de acumulação intensiva). O fordismo, teria sido, historicamente, o principal modo de desenvolvimento a abarcar um regime de acumulação intensiva com uma regulação monopolista (ou administrada).

Ainda nessa primeira geração de trabalhos, surgiram as primeiras obras que não adotavam Marx como ponto de partida. Tais obras elaboravam um ponto de vista mais 
historicista, abrindo mão de uma teoria geral do capitalismo. Desde o início da década de 1980 esse ponto de vista prevaleceu. A escola da regulação deixou de ser uma corrente voltada ao desenvolvimento e à atualização do marxismo e se voltou à elaboração de uma economia histórica e institucional.

Ao longo das décadas de 1980 e 1990, a escola da regulação se desenvolveu e se consolidou como uma corrente relevante para a compreensão do capitalismo contemporâneo. Essas décadas foram vistas como um período de continuidade da crise do fordismo. Foi somente a partir do ano 2000 que os autores regulacionistas vislumbraram a possibilidade de existência de um regime de acumulação liderado pelas finanças. A dificuldade de compreender o capitalismo posterior ao fordismo está associada a uma visão teórica inadequada acerca das características básicas do modo de produção. Alguns dos principais problemas teóricos são os pressupostos injustificados de que o capitalismo pode funcionar sem revolucionar as condições de produção e que o funcionamento normal do capitalismo contemporâneo implica em crescimento econômico elevado e estável. O projeto teórico de procurar conjugar as análises de Marx e de Keynes com a concepção correta de que o capitalismo necessita de instituições para se reproduzir é um projeto válido e promissor, mas não pode ser plenamente desenvolvido deixando de lado a análise acerca dos fundamentos do sistema econômico.

\section{Referências bibliográficas}

ABOITES, J.; MIOTTI, L.; QUENAN, C. Les approches régulationnistes et l'accumulation en Amérique latine. In: BOYER, R.; SAILLARD, Y. Théorie de la régulation: l'état des savoirs. Paris: La Découverte, 2002.

AGLIETTA, M. L'évolution des salaires en France au cours des vingt dernières années. Revue Economique, v. 22, n. 1, 1971.

AGLIETTA, M. De "Régulation et crises du capitalisme" à la "Violence de la monnaie" et au-delà. In: SEBAÏ, F.; VERCELLONE, C. (Ed.). Ecole de la régulation et critique de la raison économique. Paris: L’Harmattan (número especial da Futur Antérieur), 1994.

AGLIETTA, M. A theory of capitalist regulation: the US experience. London; New York: Verso, 2000 (1979).

AGLIETTA, M.; COURBIS, R. Un outil du plan: le modèle Fifi. Economie et Statistique, n. $1,1969$.

AMABLE, B. The diversity of modern capitalism. Oxford: Oxford University Press, 2003.

AMIN, S. A propos de la régulation. In: SEBAÏ, F.; VERCELLONE, C (Ed.). Ecole de la régulation et critique de la raison économique. Paris: L'Harmattan (número especial da FuturAntérieur), 1994. 
BASLÉ, M. Antécédents institutionnlistes méconnus ou connus de la théorie de la régulation. In: BOYER, R; SAILLARD, Y. (Ed.). Théorie de la régulation: l'état des savoirs. Paris: La Découverte. Collection Recherches, Nouvelle édition complétée, 2002.

BENASSY, J.; BOYER, R.; LIPIETZ, A. Approches de l'inflation: l'exemple français. Recherches Économiques et Sociales, La Documentation Française, n. 12, 1978.

BILLAUDOT, B. Régulation et croissance: une macroéconomie historique et institutionnelle. Paris: L'Harmattan, 2001.

BOCCARA, P. Evolution et fonctionnement économiques dans la démocratie avancée, comme phase de transition révolutionnaire au socialisme: quelques problèmes et hypothèses. Economie \& Politique, Sept. 1971.

BOCCARA, P. Estudos sobre o capitalismo monopolista de Estado. Lisboa: Editorial Estampa, 1978.

BOULLÉ, J.; BOYER, R.; MAZIER, J.; GASTON, J. Le modèle Star. Statistiques et Etudes Financieres, n. 15, 1974.

BOYER, R. La croissance française de l'après-guerre et les modèles macroéconomiques. Revueéconomique, v. 27, n. 5, 1976.

BOYER, R. A teoria da regulação: uma análise crítica. São Paulo: Nobel, 1990.

BOYER, R. Os modos de regulação na época do capitalismo globalizado: depois do boom, a crise? In: FIORI, J. L.; TAVARES, M. C.; RAMONET, I.; CASTEL, R.; HIRST, P.; BOYER, R. (Org.). Globalização: o fato e o mito. Rio de Janeiro: Ed. UERJ, 1998.

BOYER, R. Is a finance-led growth regime a viable alternative to Fordism? A pre-liminary analyse. Economy and Society, v. 29, n. 1, 2000.

BOYER, R. Théorie de la régulation, v. 1: les fondamentaux. Paris: La Découverte, Collection Repères, 2004.

BOYER, R. Les financiers détruiront-ils le capitalisme? Paris: Economica, 2011.

BOYER, R. Économie politique des capitalismes: théorie de la régulation et des crises. Paris: La Découverte, 2015.

BOYER, R.; FREYSSENET, M. O mundo que mudou a máquina: síntese dos trabalhos do GERPISA 1993-1999. Nexos Econômicos, v. 2, n. 1, 2000.

BOYER, R.; JUILLARD, M. Les États-Unis: adieu au fordisme! In: BOYER, R.; SAILLARD, Y. (Ed.). Théorie de la régulation: l'état des savoirs. Paris: La Découverte. Collection Recherches, Nouvelle édition complétée, 2002.

BOYER, R.; MISTRAL, J. Accumulation, inflation, crises. Paris: Presses Universitaires de France, 1978. 
BOYER, R.; SAILLARD, Y. (Ed.). Théorie de la régulation: l'état des savoirs. Paris: La Découverte. Collection Recherches, Nouvelle édition complétée, 2002.

BRENNER, R.; GLICK, M. The regulation approach: theory and history. New Left Review, n. $188,1991$.

BRENNER, R. Reply to critics. Comparative Studies of South Asia, Africa and the Middle East, v. XIX, n. 2, 1999.

CHANTEAU, J-P.; GROUIEZ, P.; LABROUSSE, A.; LAMARCHE, T.; MICHEL, S.; NIEDDU, M.; VERCUEIL, J. Trois questions à la théorie de la régulation par ceux qui ne l'ont pas fondée. Revue de la Régulation, 1er semester, Spring 2016.

CHAVANCE, B. Institutions, régulation et crises dans les économies socialistes. In: BOYER, R.; SAILLARD, Y. (Eds.). Théorie de la régulation: l'état des savoirs. Paris: La Découverte. Collection Recherches. Nouvelle édition complétée, 2002.

CLÉVENOT, M. Les difficultés à nommer le nouveau régime de croissance. Revue de la Régulation, l'automne 2008.

CORIAT, B. La théorie de la régulation: origines, spécificités et perspectives. In: SEBAÏ, F.; VERCELLONE, C (Ed.). Ecole de la régulation et critique de la raison économique. Paris: L’Harmattan (número especial da FuturAntérieur), 1994a.

CORIAT, B. Pensar pelo avesso: o modelo japonês de trabalho e organização. Rio de Janeiro:Ed. UFRJ/Revan, 1994b.

CORIAT, B. France: un fordisme brisé... et sans sucesseur. In: BOYER, R.; SAILLARD, Y. (Ed.). Théorie de la régulation: l'état des savoirs. Paris: La Découverte. Collection Recherches. Nouvelle édition complétée, 2002.

CORIAT, B.; DOSI, G. The institutional embeddedness of economic change: an appraisal of the "evolutionary" and "regulationist" research programmes. In: HODGOSN, G. (Ed.). A modern reader in institutional and evolutionary economics. Cheltenham: Edward Elgar, 2000.

CORIAT, B.; DOSI, G. Évolutionnisme et régulation, différences et convergences. In: BOYER, R.; SAILLARD, Y. (Ed.). Théorie de la régulation: l'état des savoirs. Paris: La Découverte. Collection Recherches. Nouvelle édition complétée, 2002.

FIORI, J. L.; TAVARES, M. C.; RAMONET, I.; CASTEL, R.; HIRST, P.; BOYER, R. (Org.). Globalização: o fato e o mito. Rio de Janeiro: Ed. UERJ, 1998.

HUSSON, M. The regulation school: a one-way thicket from Marx to social liberalism? In: BIDET, J.; KOUVELAKIS, S. Critical companion to contemporary Marxism. Chicago: Haymarket Books, 2009.

JESSOP, B.; N. L. SUM. Beyond the regulation approach: putting capitalist economies in their place. Cheltenham: Edward Elgar, 2006. 
Marcelo Soares Bandeira de Mello Filho

JESSOP, B.; N. L. SUM. Beyond the 'Approach in Terms of Régulation'? Revue de la Régulation, 1er semestre, Spring 2016.

LAMARCHE, T. Des limites de la régulation... qui peuvent en cacher d'autres. Revue de la Régulation, l'automne 2012.

LIPIETZ, A. Le monde enchanté: de la valeur à l'envol inflationniste. Paris: La Découverte, 1983.

LIPIETZ, A. Miragens e milagres. Problemas da industrialização do terceiro mundo. São Paulo: Nobel, 1988.

LIPIETZ, A. The fortunes and misfortunes of post-fordism. In: ALBITTRON, R.; ITOH, M.; WESTRA, R.; ZUEGE, A. Phases of capitalist development: booms, crises, and globalizations. New York: Palgrave, 2001.

LIPIETZ, A. La trop évitable crise européenne. In: AUFFREY-SÉGUETTE, M.; FERRY, J.M. LECLERC, A. Crise et critique. Paris: Presses Univ. de Paris-Sorbonne, 2015.

LORDON, F. Changement d'époque? In: LORDON, F. Jusqu'à quand? Pour en finir avec les crises financières. Paris: Ed. Raisons d'Agir, 2008.

MAVROUDEAS, S. Social structures of accumulation, regulation approach and stages theory. In: MCDONOUGH, T.; REICH, M.; KOTZ, D.; GONZALES-PEREZ. Growth and crises: social structure of accumulation theory and analysis. Galway: National University of Ireland, 2006. Disponível em: http://ssagalway.blogspot.com. Acesso em: 10 jun. 2010.

MEDEIROS, C. Globalização, mercados e instituições segundo a perspectiva regulacionista: uma análise crítica. In: FlORI, J. L.; TAVARES, M. C.; RAMONET, I.; CASTEL, R.; HIRST, P.; BOYER, R. (Org.). Globalização: o fato e o mito. Rio de Janeiro: Ed. UERJ, 1998.

MELlO FILHO, M. Escola francesa da regulação, escola da estrutura social de acumulação e as etapas do capitalismo. Tese (Doutorado em Economia)-Universidade Federal de Minas Gerais, Cedeplar, Belo Horizonte, 2016.

NASCIMENTO, E. P. Notas a respeito da escola francesa de regulação. Revista de Economia Política, v. 13, n. 2, 1993.

NEGRI, T. L'école de la régulation face à des nouveaux problémes. In: SEBAÏ, F.; VERCELLONE, C (Ed.). Ecole de la régulation et critique de la raison économique. Paris: L’Harmattan (número especial da FuturAntérieur), 1994.

POSSAS, M. L. O projeto teórico da "escola da regulação": alguns comentários. Novos Estudos Cebrap, n. 21, 1988.

ROSDOLSKY, R. Gênese e estrutura de O Capital de Karl Marx. Rio de Janeiro: Ed. UERJ/Contraponto, 2001. 
THÉRET, B. Introdução: a teoria da regulação e as transformações contemporâneas do sistema internacional, dos Estados e da economia mundial. In: THÉRET, B.; BRAGA, J. Regulação econômica e globalização. Campinas, Unicamp. IE, 1998.

THÉRET, B. État, finances publiques et régulation. In: BOYER, R.; SAILLARD, Y. (Ed.). Théorie de la régulation: l'état des savoirs. Paris: La Découverte. Collection Recherches. Nouvelle édition complétée, 2002.

VIDAL, J. Birth and growth of the French regulation school in the French intellectual context. In: LABROUSSE, A.; WEISZ, J. Institutional economics in France and Germany: German Ordoliberalism versus the French Regulation School. Berlin: Springer, 2001.

VILLEVAL, M.-C. Une théorie économique des institutions? In: BOYER, R.; SAILLARD, Y. (Ed.). Théorie de la régulation: l'état des savoirs. Paris: La Découverte. Collection Recherches, Nouvelle édition complétée, 2002. 